\title{
Outcomes after Contralateral Anatomic Surgical Resection in Multiple Lung Cancer
} \author{
Jonathan Meynier ${ }^{3}$ Pascal Berna ${ }^{1}$ \\ 1 Department of Thoracic Surgery, Amiens University Hospital, \\ Amiens, France \\ 2 Department of Thoracic and Vascular Surgery, Victor Dupouy \\ Hospital, Argenteuil, France \\ ${ }^{3}$ Department of Biostatistics, Clinical Research and Innovation \\ Directorate, Amiens University Hospital, Amiens, France
}

Alex Fourdrain ${ }^{1}$ Patrick Bagan ${ }^{1,2}$ Olivier Georges ${ }^{1}$ Sophie Lafitte ${ }^{1} \quad$ Florence De Dominicis $^{1}$

Thorac Cardiovasc Surg 2021;69:373-379.

\begin{abstract}
Address for correspondence Alex Fourdrain, MD, Department of Thoracic Surgery, Amiens University Hospital, F-80054 Amiens, France (e-mail: fourdrain.alex@chu-amiens.fr).
\end{abstract}

\begin{abstract}
Background Patients treated surgically for lung cancer may present synchronous or metachronous lung cancers. The aim of this study was to evaluate outcomes after a second contralateral anatomic surgical resection for lung cancer.

Methods We performed a retrospective two-center study, based on a prospective indexed database. Included patients were treated surgically by bilateral anatomic surgical resection for a second primary lung cancer. We excluded nonanatomic resections, benign lesions, and ipsilateral second surgical resections.

Results Between January 2011 and September 2018, 55 patients underwent contralateral anatomic surgical resections for lung cancer, mostly for metachronous cancers. The first surgical resection was a lobectomy in most cases (45 lobectomies: $81.8 \%, 9$ segmentectomies: $16.4 \%$, and 1 bilobectomy: $1.8 \%$ ), and a video-assisted thoracic surgery (VATS) procedure was used in 23 cases (41.8\%). The mean interval between the operations was 38 months, and lobectomy was less frequent for the second surgical resection (35 lobectomies: $63.6 \%$ and 20 segmentectomies: $36.4 \%$ ), with VATS procedures performed in 41 cases $(74.5 \%)$. Ninety-day mortality was $10.9 \%(n=6)$, and 3-year survival was $77 \%$. Risk factor analysis identified the number of resected segments during the second intervention or the total number of resected segments,

Keywords

- lung cancer

- lobectomy

- multiple primary

- mortality

- survival extent of resection (lobectomy vs. segmentectomy), surgical approach (thoracotomy vs. VATS), tumor stage, and nodal involvement as potential prognostic factors for longterm survival.

Conclusion A second contralateral anatomic surgical resection for multiple primary lung cancer is possible, with a higher early mortality rate, but acceptable long-term survival, and should be indicated for carefully selected patients.
\end{abstract}

\section{Introduction}

Surgical anatomic lung resection with systematic lymph node dissection is the recommended treatment for earlystage non-small cell lung cancer, with an estimated postop- erative mortality of $\sim 2.8 \%$ at 30 days and $5.4 \%$ at 90 days. ${ }^{1}$ Second or multiple primary lung cancer was first described in 1924 by Beyreuther, ${ }^{2}$ and its current incidence is estimated at 0.2 to $20 \%$ of cases. ${ }^{3}$ Martini and Melamed proposed a spatiotemporal pathology-based classification in 1975 to received

January 28, 2020

accepted after revision

March 9, 2020

published online

May 22, 2020 (c) 2020. Thieme. All rights reserved.

Georg Thieme Verlag KG,

Rüdigerstraße 14,

70469 Stuttgart, Germany
DOI https://doi.org/

10.1055/s-0040-1710068. ISSN 0171-6425. 
distinguish between synchronous and metachronous multiple primary lung cancers and between these cancers and metastasis. ${ }^{4}$ Based on these criteria, recent studies have suggested that the incidence of a second synchronous lung cancer is $4.5 \%$ of cases, ${ }^{5}$ whereas the incidence of a second metachronous lung cancer is 5 to $10 \%$ of cases. ${ }^{6}$ There are currently no well-defined guidelines concerning the care strategy for these patients, and the type of treatment may differ according to the specialty of the consultant, ${ }^{7}$ although repeat surgery seems to be the best option in eligible patients. ${ }^{8}$ In this study, we evaluated early postoperative morbidity and mortality, and long-term survival outcomes in patients treated for multiple primary lung cancer by sequential bilateral anatomic surgical resection.

\section{Patients and Methods}

\section{Patients}

We performed a retrospective study at two centers in our country, over an 8-year period, from January 2011 to September 2018. We included all consecutive cases of patients treated surgically by anatomic resection for bilateral multiple lung cancer (synchronous or metachronous) identified by analysis of the multidisciplinary meeting decision in our institutional indexed database. We excluded patients treated by nonanatomic sublobar resection, patients treated for indications other than primary lung cancer (benign tumors, secondary cancer lesions), and patients with multiple primary tumors on the same side as the initial intervention. As an observational retrospective study based on an indexed prospective database (ref. DRCI-T38), patients' data were already anonymized and were used in accordance with our Institutional Review Board policy, without requirement for a supplemental ethic committee consent. A signed informed consent was obtained from every patient registered in this database.

Open approach procedures were performed with posterolateral thoracotomy in the fifth intercostal space, with half section of the posterior part of the latissimus dorsi muscle and preservation of the serratus anterior muscle. Video-assisted thoracic surgery (VATS)-based procedures were performed fully endoscopically with an anterior approach to the hilum placing all three ports in the seventh intercostal space.

\section{Study Outcomes}

The main outcome measures were early postoperative mortality after contralateral anatomic lung resection (evaluated 90 days after surgery) and overall survival. The secondary outcome measures analyzed were postoperative morbidity and risk factors affecting long-term survival after contralateral anatomic lung resection.

\section{Statistical Analysis}

Continuous patient variables are expressed as the mean \pm standard deviation, and dichotomous or categorical variables are expressed as frequencies and percentages. Statistical analysis was performed with SAS software (version 9.4, SAS Institute Inc., Cary, North Carolina, United States). Lung cancer stage was determined according to the eighth edition of the American Joint Committee on Cancer manual for TNM status. Early postoperative mortality is expressed as a frequency and percentage, and long-term survival was estimated with Kaplan-Meier's curves. Risk factors for long-term survival were investigated by univariate Cox-model regression analysis. The threshold for statistical significance was set at $p \leq 0.05$.

\section{Results}

\section{Patient Characteristics}

Fifty-five patients met the inclusion criteria for this study. The characteristics of these patients are summarized in - Table 1. The rates of VATS approach (74.5 vs. $41.8 \%, p$ $\leq 0.001$ ), and segmental resection ( 16.4 vs. $36.4 \%, p=0.02$ ), were higher for the second surgical resection than for the first. The pathological findings for the two surgical resections

Table 1 Patient characteristics

\begin{tabular}{|c|c|}
\hline Characteristics & $\begin{array}{l}\text { Value } n(\%) \text { or } \\
\text { mean } \pm \text { SD }\end{array}$ \\
\hline \multicolumn{2}{|l|}{ First surgery } \\
\hline Side of the first intervention & $\begin{array}{l}30 \text { right }(53.7 \%)-25 \\
\text { left }(46.3 \%)\end{array}$ \\
\hline VATS approach & $23(41.8 \%)$ \\
\hline Segmentectomy & $9(16.4 \%)$ \\
\hline Lobectomy & $45(81.8 \%)$ \\
\hline Bilobectomy & $1(1.8 \%)$ \\
\hline Mean number of segments resected & $3.7 \pm 1.2$ \\
\hline \multicolumn{2}{|l|}{ Comorbidities before second surgery } \\
\hline Age at second surgery & $65.9 \pm 8.6$ \\
\hline Male & $41(74.5 \%)$ \\
\hline Prior ENT cancer & $7(12.7 \%)$ \\
\hline Type 2 diabetes & $5(9.1 \%)$ \\
\hline Cardiac arrhythmia & $4(7.3 \%)$ \\
\hline Ischemic heart disease & $7(12.7 \%)$ \\
\hline BMI & $25.4 \pm 5.1$ \\
\hline Albumin $(\mathrm{g} / \mathrm{L})$ & $38.9 \pm 5.3$ \\
\hline Prealbumin $(\mathrm{g} / \mathrm{L})$ & $0.27 \pm 0.07$ \\
\hline \multicolumn{2}{|l|}{ Interval between operations } \\
\hline Interval between resections (mo) & $38.4 \pm 40$ \\
\hline Preoperative FEV1 (\%) & $74.4 \pm 17.6$ \\
\hline Predicted postoperative FEV1 (\%) & $56.1 \pm 15.5$ \\
\hline \multicolumn{2}{|l|}{ Second surgery } \\
\hline VATS approach & $41(74.5 \%)$ \\
\hline Segmentectomy & $20(36.4 \%)$ \\
\hline Lobectomy & $35(63.6 \%)$ \\
\hline Number of segments resected & $3.4 \pm 1.3$ \\
\hline Total number of resected segments & $7.1 \pm 1.7$ \\
\hline
\end{tabular}

Abbreviations: BMI, body mass index; ENT, ear, nose, and throat; FEV1, forced expiratory volume in 1 second; SD, standard deviation; VATS, video-assisted thoracoscopic surgery. 
are displayed in - Table 2 . The proportion of patients undergoing surgery for metachronous multiple lung cancer was higher than the proportion of patients with synchronous multiple lung cancer. Adenocarcinoma predominated, and a concordance of histological subtype was observed in 42 patients (76.4\%) (-Table 3). Complete resection (R0) was achieved in all patients, and 11 patients received multimodal treatment (20\%). The mode and time frame for chemotherapy and/or radiotherapy are summarized in - Table 3.

\section{Early and Late Postoperative Outcomes}

Early postoperative mortality was assessed in 6 of 55 patients (10.9\%) within 90 days of surgery. The causes of death were postoperative pneumonia and its consequences in five patients (9.1\%), and early postoperative acute respiratory distress syndrome in one patient (1.8\%). The results,

Table 2 Pathological findings

\begin{tabular}{|c|c|}
\hline Characteristics & Number of patients, $n(\%)$ \\
\hline \multicolumn{2}{|l|}{ First surgery } \\
\hline \multicolumn{2}{|l|}{ Histology } \\
\hline Adenocarcinoma & $41(74.5 \%)$ \\
\hline Squamous cell carcinoma & $11(20 \%)$ \\
\hline Other & $3(5.5 \%)$ \\
\hline \multicolumn{2}{|l|}{ T stage } \\
\hline $\mathrm{T} 1$ & $37(67.3 \%)$ \\
\hline $\mathrm{T} 2$ & $13(23.6 \%)$ \\
\hline $\mathrm{T} 3$ & $3(5.5 \%)$ \\
\hline $\mathrm{T} 4$ & $2(3.6 \%)$ \\
\hline \multicolumn{2}{|l|}{$\mathrm{N}$ and $\mathrm{M}$ stages } \\
\hline No & $48(87.3 \%)$ \\
\hline N1 & $2(3.6 \%)$ \\
\hline N2 & $5(9.1 \%)$ \\
\hline M1 & $2(3.6 \%)$ \\
\hline \multicolumn{2}{|l|}{ Second surgery } \\
\hline \multicolumn{2}{|l|}{ Histology } \\
\hline Adenocarcinoma & $41(74.5 \%)$ \\
\hline Squamous cell carcinoma & $7(12.7 \%)$ \\
\hline Other & $7(12.7 \%)$ \\
\hline \multicolumn{2}{|l|}{ T stage } \\
\hline $\mathrm{T} 1$ & $43(78.2 \%)$ \\
\hline $\mathrm{T} 2$ & $10(18.2 \%)$ \\
\hline $\mathrm{T} 3$ & $2(3.6 \%)$ \\
\hline $\mathrm{T} 4$ & $0(0 \%)$ \\
\hline \multicolumn{2}{|l|}{$\mathrm{N}$ and $\mathrm{M}$ stages } \\
\hline No & $52(94.5 \%)$ \\
\hline N1 & $1(1.8 \%)$ \\
\hline N2 & $2(3.6 \%)$ \\
\hline M1 & $2(3.6 \%)$ \\
\hline
\end{tabular}

Table 3 Chronology of multiple primary lung cancer and the multimodal treatment administered

\begin{tabular}{|c|c|}
\hline Characteristics & $\begin{array}{l}\text { Number of } \\
\text { patients, } n(\%)\end{array}$ \\
\hline \multicolumn{2}{|l|}{ Chronology of multiple lung cancer } \\
\hline Metachronous & $28(50.9 \%)$ \\
\hline Synchronous & $25(45.5 \%)$ \\
\hline $\begin{array}{l}\text { Metastatic (M1a-tumor in } \\
\text { contralateral lung) }\end{array}$ & $2(3.6 \%)$ \\
\hline Histology subtype concordance rate & $42(76.4 \%)$ \\
\hline AdenoCa-AdenoCa & $36(65.5 \%)$ \\
\hline SCC-SCC & $6(10.9 \%)$ \\
\hline AdenoCa-other & $5(9.1 \%)$ \\
\hline SCC-other & $6(10.9 \%)$ \\
\hline Other & $2(3.6 \%)$ \\
\hline \multicolumn{2}{|l|}{ Multimodal treatment } \\
\hline $\begin{array}{l}\text { First surgery, neoadjuvant } \\
\text { ChemoTx (synchronous) }\end{array}$ & $1(1.8 \%)$ \\
\hline $\begin{array}{l}\text { First surgery, neoadjuvant } \\
\text { ChemoTx (metachronous) }\end{array}$ & $1(1.8 \%)$ \\
\hline $\begin{array}{l}\text { First surgery adjuvant } \\
\text { ChemoTx for } \geq \mathrm{T} 2 \mathrm{~b} \text { or } \\
\mathrm{N}+\text { (metachronous) }\end{array}$ & $8(14.5 \%)$ \\
\hline Interval ChemoTx (synchronous) & $1(1.8 \%)$ \\
\hline $\begin{array}{l}\text { Second surgery, adjuvant } \\
\text { ChemoTx for } \geq \mathrm{T} 2 \mathrm{~b} \text { or } \mathrm{N}+\end{array}$ & $5(9.1 \%)$ \\
\hline
\end{tabular}

Abbreviations: AdenoCa, adenocarcinoma; ChemoTx, chemotherapy; SCC, squamous cell carcinoma.

Table 4 Postoperative morbidity and mortality after contralateral surgery

\begin{tabular}{|l|l|}
\hline Characteristics & $\begin{array}{l}\text { Number of patients, } \\
\boldsymbol{n}(\%) / \text { value (\%) }\end{array}$ \\
\hline Pneumonia & $13(23.6 \%)$ \\
\hline Need for bronchoscopy & $13(23.6 \%)$ \\
\hline Reintubation & $4(7.3 \%)$ \\
\hline Cardiac arrhythmia & $5(9.1 \%)$ \\
\hline Bronchopleural fistula & $2(3.6 \%)$ \\
\hline Laryngeal paralysis & $4(7.3 \%)$ \\
\hline Chest tube duration & $6.7 \pm 6.2 \mathrm{~d}$ \\
\hline Length of stay & $9.2 \pm 6.3 \mathrm{~d}$ \\
\hline 30-d mortality & $5(9.1 \%)$ \\
\hline 90-d mortality & $6(10.9 \%)$ \\
\hline
\end{tabular}

including those for postoperative morbidity are summarized in - Table 4.

Overall survival was estimated at $83.4 \%$ at 1 year, $77 \%$ at 3 years, and $72.7 \%$ at 5 years; median overall survival was not reached, for a median duration of follow-up of 28 months (range: 0-95 months) (-Fig. 1). The cause of death was lung 


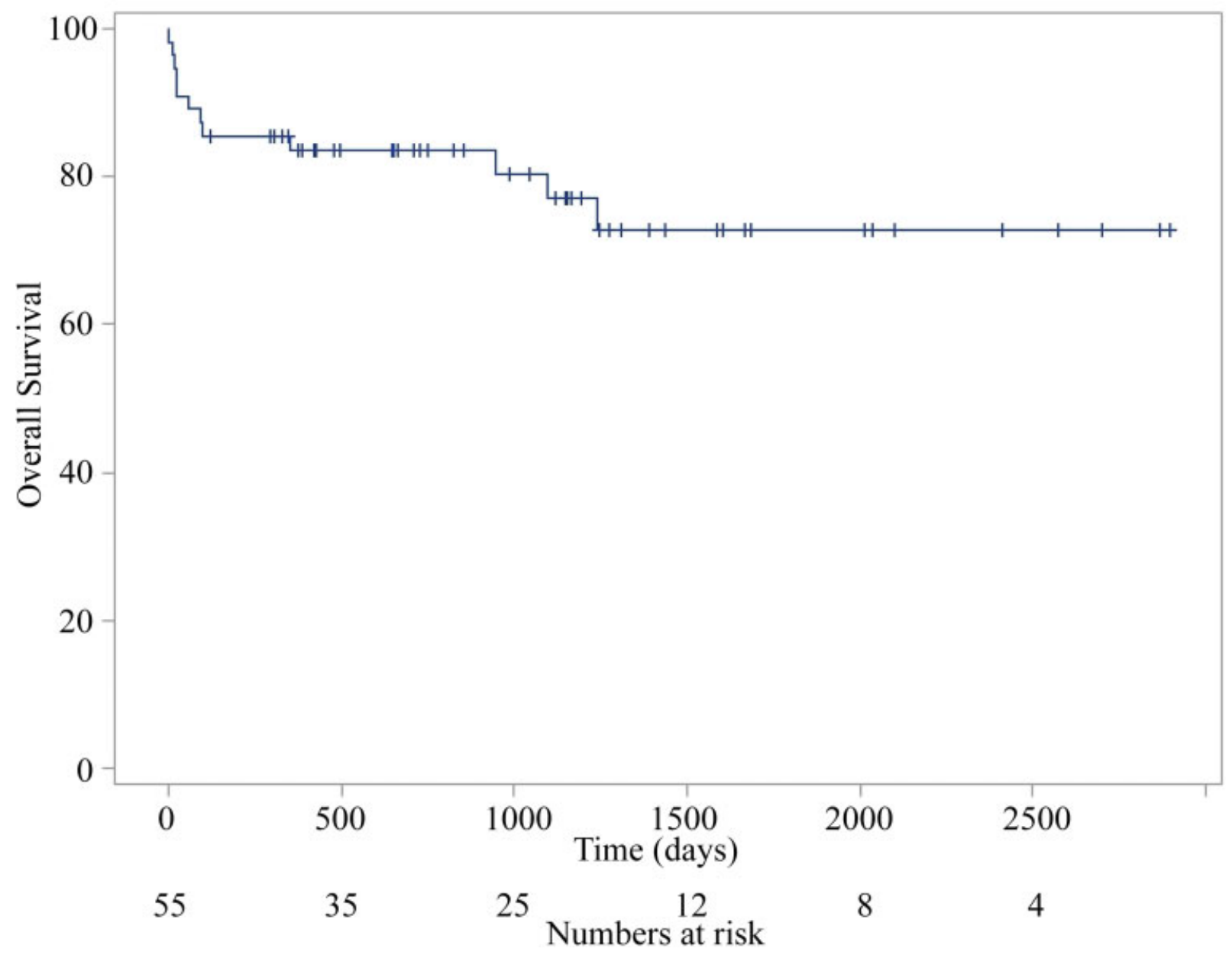

Fig. 1 Overall survival following second contralateral anatomic surgical resections for lung cancer.

cancer recurrence in two of the six patients who died more than 90 days after surgery. Disease-free survival was estimated at $79.9 \%$ at 1 year, $63.8 \%$ at 3 years, and $63.8 \%$ at 5 years: median disease-free survival was not reached, for a median duration of follow-up of 23 months (range: 0-95 months) (-Fig. 2).

Analysis of Risk Factors for Long-Term Overall Survival All patients were followed up. Univariate Cox-model regression analysis showed that overall survival outcomes were worse for patients undergoing surgery for advanced-stage lung cancers at the second resection than for those undergoing a second resection for a stage T1 tumor (for T2 stage: odds ratio $[\mathrm{OR}]=5.08$ [95\% confidence interval, $\mathrm{CI}$ : $1.51-$ 17.11]; for $\mathrm{T} 3$ stage: $\mathrm{OR}=3.49$ [95\% CI: 0.42-29.01], $p=0.03$ ). Patients without pathologic node involvement tended to have a better prognosis $(\mathrm{OR}=0.30[95 \% \mathrm{CI}$ : $0.07-1.36$ ], $p=0.12$ ) (-Table 5). A limited extent of parenchymal resection, including a smaller total number of segments resected, tended to have a favorable impact on overall survival ( $\mathrm{OR}=1.30$ [95\% Cl: 0.95-1.79], $p=0.10$ ). Overall survival was also tended to be better in patients treated by segmentectomy at the second resection than in those treated by lobectomy ( $\mathrm{OR}=6.46$ [95\% CI: 0.83-50.22], $p=0.07$ ) (-Table 5). The use of a VATS approach also tended to be associated with better overall survival ( $\mathrm{OR}=2.99[95 \% \mathrm{CI}$ : 0.96-9.29], $p=0.06$ ) (-Table 5).

\section{Discussion}

Several authors have reported early and late outcomes in patients with multiple synchronous ${ }^{5,9-13}$ or metachronous ${ }^{14-16}$ lung cancers. These studies evaluated ipsilateral and contralateral multiple primary lung cancers, often considering data for both these situations, but few studies have specifically described outcomes following contralateral surgical resection. ${ }^{12,17-20}$ De Leyn et al reported results for a cohort of 36 patients treated by bilateral lung resection for lung cancer, including 10 patients undergoing bilateral anatomic resection (lobectomy). They reported an early postoperative mortality of $2.8 \%$ and a 5 -year survival rate of $38 \%{ }^{17}$ (- Table 6 ). Shah et al reported results for a cohort of 47 patients, including 11 bilateral anatomic resections (6 lobectomy/segmentectomy and 5 lobectomy/lobectomy), with an early postoperative mortality of $2 \%$ and a 3-year survival rate of $35 \%{ }^{18}$ ( - Table 6). Hattori et al reported an early postoperative mortality of $23.9 \%$ and a 5 -year survival rate of $61.7 \%$ for a cohort of 21 patients, all treated by bilateral lobectomy ${ }^{19}$ ( - Table 6 ). A larger cohort (88 patients) studied by Yang et al, including 39 bilateral anatomic resections, had an early postoperative mortality of $0 \%$ and 3 - and 5-year 


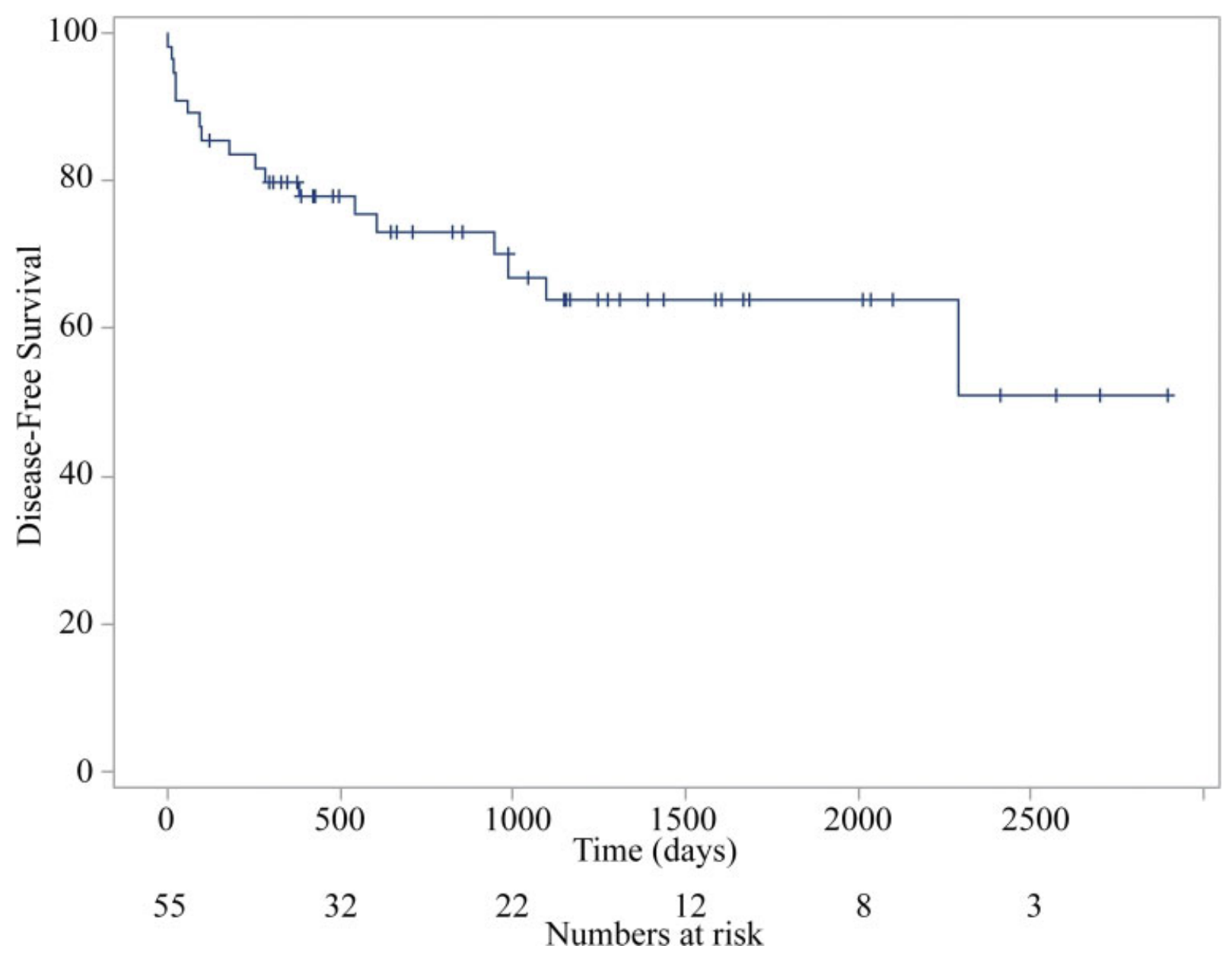

Fig. 2 Disease-free survival following second contralateral anatomic surgical resections for lung cancer.

Table 5 Analysis of risk factors for overall survival

\begin{tabular}{|l|l|}
\hline Prognostic factor for OS & $p$-Value, hazard ratio (95\% CI) \\
\hline $\begin{array}{l}\text { Small total number } \\
\text { of resected segments }\end{array}$ & $p=0.10,1.30(0.95-1.79)$ \\
\hline $\begin{array}{l}\text { Segmental resection } \\
\text { (vs. lobar) }\end{array}$ & $p=0.07,6.46(0.83-50.22)$ \\
\hline VATS for second surgery & $p=0.06,2.99(0.96-9.29)$ \\
\hline $\begin{array}{l}\text { Tumor stage after } \\
\text { second surgery }\end{array}$ & $p=0.03$ \\
\hline T1 & 1 \\
\hline T2 & $5.08(1.51-17.11)$ \\
\hline T3 & $3.49(0.42-29.01)$ \\
\hline $\begin{array}{l}\text { No nodal involvement } \\
\text { (vs. nodal involvement) }\end{array}$ & $p=0.12,0.30(0.07-1.36)$ \\
\hline
\end{tabular}

Abbreviations: $\mathrm{Cl}$, confidence interval; VATS, video-assisted thoracoscopic surgery.

survival rates of 84.5 and $75 \%$, respectively ${ }^{20}$ (- Table 6). Our results were consistent with these previous findings for higher proportions of anatomic resection, with an early postoperative mortality of double or almost triple that for the first resection, ${ }^{1}$ and an overall survival of $77 \%$ at 3 years and $72.7 \%$ at 5 years after bilateral anatomical resection (-Table 6 ). The previous retro- spective studies did not assess differences in long-term survival between anatomic and nonanatomic resections for bilateral primary lung cancer, despite the reported trend toward better survival in patients undergoing anatomic resections. ${ }^{17,18,20} \mathrm{~A}$ recent study involving a propensity score analysis of 454 pairs of matched patients revealed better long-term survival outcomes for patients treated by bilateral lobectomy than for those treated by sublobectomy, particularly for stage I multiple primary lung cancer, following a first resection performed by lobectomy in $85 \%$ of patients, and including mostly bilateral lesions (80 vs. $20 \%$ ipsilateral). ${ }^{21}$ However, the proportions of anatomic segmentectomy and nonanatomic sublobar resection among the interventions were unknown for the sublobectomy group. ${ }^{21}$

Only Hattori et al have analyzed the risk factors of inhospital death (early postoperative mortality). They identified age older than 70 years, higher tumor stage, right lower lobectomy, and bilateral lower lobectomy as factors independently associated with a poor prognosis. ${ }^{19}$ The findings of our univariate analysis suggest that impaired lung function and a larger total number of resected segments are also risk factors for in-hospital death.

Yang et al found that age, sex, tumor size, nodal stage, extent of surgery (lobectomy vs. sublobectomy), year of diagnosis, histologic type, and pathologic stage of the initial cancer were prognostic predictors of long-term survival in multiple primary 
Table 6 Findings of previous studies for early postoperative mortality and long-term survival after bilateral lung resection for multiple primary lung cancer

\begin{tabular}{|c|c|c|c|c|c|}
\hline & $\begin{array}{l}\text { Number of } \\
\text { patients }\end{array}$ & $\begin{array}{l}\text { Anatomic resection } \\
n(\%)\end{array}$ & $\begin{array}{l}\text { Early postoperative } \\
\text { mortality }\end{array}$ & 3-y survival & 5-y survival \\
\hline De Leyn et al (2008) ${ }^{17}$ & 36 & $10 / 36(27.8 \%)$ & $2.8 \%$ & NR & $38 \%$ \\
\hline Kocaturk et al $(2011)^{12}$ & 12 & $7 / 12(58.3 \%)$ & $8.3 \%$ & NR & $62.8 \%$ \\
\hline Shah et al $(2012)^{18}$ & 47 & $11 / 47(23.4 \%)$ & $2 \%$ & $35 \%$ & $29 \%$ \\
\hline Hattori et al $(2015)^{19}$ & 21 & $21 / 21(100 \%)$ & $23.9 \%$ & NR & $61.7 \%$ \\
\hline Yang et al $(2016)^{20}$ & 88 & $39 / 88(44.3 \%)$ & $0 \%$ & $84.5 \%$ & $75 \%$ \\
\hline Current study (2020) & 55 & $55 / 55(100 \%)$ & $10.9 \%$ & $77 \%$ & $72.7 \%$ \\
\hline
\end{tabular}

Abbreviation: NR, not reported.

lung cancer. ${ }^{21}$ This study by Yang et al is the largest performed to date, but the proportions of anatomic/nonanatomic resections were not detailed in the sublobectomy group, preoperative lung function tests and intraoperative lymphadenectomy were not reported, and $20 \%$ of the patients in the cohort were treated for ipsilateral lesions. ${ }^{20}$ Some previous studies focused specifically on bilateral surgery for multiple primary lung cancer, with much smaller population samples, and found no differences in survival between resection types or histologic features. ${ }^{17,19}$ However, Yang et al found that a higher tumor or nodal stage, the presence of more than two pulmonary lesions, and similar histologic features between the multiple primary lung cancers were negative prognostic factors for long-term survival in a cohort of 88 patients including 39 bilateral anatomic resections. ${ }^{20}$ Our results are consistent with these findings, as they indicate a poorer prognosis in patients with higher tumor stages and nodal involvement, in a cohort of 55 patients treated by bilateral anatomic resection with systematic lymph node dissection. We also present new data concerning the impact of surgical approach, highlighting the positive prognostic value of VATS resection, and of a smaller number of resected segments at second surgery or cumulative, limited anatomic resection (favoring anatomic segmental over lobar resection).

The sequence of surgery in case of synchronous multiple primary lung cancer has not been studied. If a segmentectomy and a contralateral lobectomy are both required, our institutional strategy is to perform the segmentectomy as the first lung resection, to preserve lung function prior to the lobar resection, and to decrease the incidence of postoperative complications.

Based on our results and those of previous studies, patient selection appears to be crucial when considering bilateral multiple primary lung cancer surgery. A meticulous multimodal preoperative nodal assessment is required, and the importance of minimally invasive surgery and sublobar anatomic resection approaches in multiple primary lung cancer surgery should be stressed.

This study has several strengths and limitations. Its main limitation is the small sample size, with only 55 patients evaluated, which made it possible to perform a univariate logistic regression analysis of risk factors, but not a multivariate analysis. Nevertheless, unlike many other published studies, it included a homogeneous cohort, with all patients treated bilaterally for multiple primary lung cancer (synchronous or metachronous), by anatomic resection with systematic radical lymph node dissection. A second limitation is the retrospective design of the study, leading to potential biases, which were minimized by the use of a prospective indexed database with a follow-up rate of $100 \%$ and evaluation at two centers. Another limitation was the merging into a single cohort of synchronous and metachronous lung cancers, defined according to the Martini and Melamed criteria, ${ }^{4}$ as these two types of cancers may have different outcomes. Moreover, we had too few data for molecular biology evaluations in these patients, and such studies may become essential in the future, to move beyond the current dichotomous criteria, which have been in place for 40 years. $^{22}$ Finally, we report the early and late outcomes of a strategy of repeat surgery for bilateral lesions. A comparison of our data with those for a multimodal approach (stereotactic ablative body radiotherapy or percutaneous ablative techniques) would have given a certain perspective to our results, but recent reports have suggested that outcomes are better for repeat surgery strategies. ${ }^{8}$

In conclusion, a second, contralateral anatomic surgical resection for synchronous or metachronous lung cancer is possible, with a higher early mortality rate than for the first resection, but acceptable long-term survival. The identification of risk factors should make it possible to select patients carefully, through meticulous preoperative evaluation, and to propose minimally invasive surgery and sublobar anatomic resection approaches for multiple primary lung cancer resection.

\section{Note}

This article was submitted and accepted for the Poster Session at the 27th European Conference on General Thoracic Surgery in Dublin, Ireland, June 9-12, 2019.

\section{Conflict of Interest}

None declared.

\section{References}

1 Pezzi CM, Mallin K, Mendez AS, Greer Gay E, Putnam JB Jr. Ninetyday mortality after resection for lung cancer is nearly double 30day mortality. J Thorac Cardiovasc Surg 2014;148(05):2269-2277

2 Beyreuther, H. Multiplicität von Carcinomen bei einem Fall von sog. "Schneeberger" Lungenkrebs mit Tuberkulose. Virchows Arch Path Anat 1924;250:230-243. https://doi.org/10.1007/BF01891568 
3 Rea F, Zuin A, Callegaro D, Bortolotti L, Guanella G, Sartori F. Surgical results for multiple primary lung cancers. Eur J Cardiothorac Surg 2001;20(03):489-495

4 Martini N, Melamed MR. Multiple primary lung cancers. J Thorac Cardiovasc Surg 1975;70(04):606-612

5 Trousse D, Barlesi F, Loundou A, et al. Synchronous multiple primary lung cancer: an increasing clinical occurrence requiring multidisciplinary management. J Thorac Cardiovasc Surg 2007; 133(05):1193-1200

6 Vansteenkiste J, De Ruysscher D, Eberhardt WE, et al; ESMO Guidelines Working Group. Early and locally advanced nonsmall-cell lung cancer (NSCLC): ESMO Clinical Practice Guidelines for diagnosis, treatment and follow-up. Ann Oncol 2013;24 (Suppl 6):vi89-vi98

7 Leventakos K, Peikert T, Midthun DE, et al. Management of multifocal lung cancer: results of a survey. J Thorac Oncol 2017; 12(09):1398-1402

8 Zhou H, Kang X, Dai L, et al. Efficacy of repeated surgery is superior to that of non-surgery for recurrent/second primary lung cancer after initial operation for primary lung cancer. Thorac Cancer 2018;9(08):1062-1068

9 Chang YL, Wu CT, Lee YC. Surgical treatment of synchronous multiple primary lung cancers: experience of 92 patients. J Thorac Cardiovasc Surg 2007;134(03):630-637

10 Fabian T, Bryant AS, Mouhlas AL, Federico JA, Cerfolio RJ. Survival after resection of synchronous non-small cell lung cancer. J Thorac Cardiovasc Surg 2011;142(03):547-553

11 Jung EJ, Lee JH, Jeon K, et al. Treatment outcomes for patients with synchronous multiple primary non-small cell lung cancer. Lung Cancer 2011;73(02):237-242

12 Kocaturk CI, Gunluoglu MZ, Cansever L, et al. Survival and prognostic factors in surgically resected synchronous multiple primary lung cancers. Eur J Cardiothorac Surg 2011;39(02): 160-166

13 Voltolini L, Rapicetta C, Luzzi L, et al. Surgical treatment of synchronous multiple lung cancer located in a different lobe or lung: high survival in node-negative subgroup. Eur J Cardiothorac Surg 2010;37(05):1198-1204

14 Battafarano RJ, Force SD, Meyers BF, et al. Benefits of resection for metachronous lung cancer. J Thorac Cardiovasc Surg 2004;127 (03):836-842

15 Mathisen DJ, Jensik RJ, Faber LP, Kittle CF. Survival following resection for second and third primary lung cancers. J Thorac Cardiovasc Surg 1984;88(04):502-510

16 Zhao H, Yang H, Han K, et al. Clinical outcomes of patients with metachronous second primary lung adenocarcinomas. OncoTargets Ther 2017;10:295-302

17 De Leyn P, Moons J, Vansteenkiste J, et al. Survival after resection of synchronous bilateral lung cancer. Eur J Cardiothorac Surg 2008;34(06):1215-1222

18 Shah AA, Barfield ME, Kelsey CR, et al. Outcomes after surgical management of synchronous bilateral primary lung cancers. Ann Thorac Surg 2012;93(04):1055-1060, discussion 1060

19 Hattori A, Suzuki K, Takamochi K, Oh S. Is bilateral pulmonary lobectomy feasible in patients with bilateral lung cancers? Thorac Cardiovasc Surg 2015;63(07):589-596

20 Yang H, Sun Y, Yao F, et al. Surgical therapy for bilateral multiple primary lung cancer. Ann Thorac Surg 2016;101(03):1145-1152

21 Yang X, Zhan C, Li M, et al. Lobectomy versus sublobectomy in metachronous second primary lung cancer: a propensity score study. Ann Thorac Surg 2018;106(03):880-887

22 Stiles BM. Say goodbye to Martini and Melamed: genomic classification of multiple synchronous lung cancer. J Thorac Dis 2017;9 (01):E87-E88 